\title{
Arts Council England: Ramifications of Organisational Dynamics and Institutional Setting on Policy
}

\begin{abstract}
This paper offers a view of the development of decision making and policy within the Arts Council, national development agency for the arts, and explores the notion of how strategies are often the outcome of resource, political and cultural processes rather than discrete strategic planning. For the purposes of this paper, decision making and policy making are being treated as synonymous as key expressions of strategy. The paper is based on an examination of the assumption with which the Arts Council historically has justified both its general operations and particular decisions, the aim being to identify the various ideological and structural determinants which bear upon its decision-making processes. The paper concludes that the Arts Council is influenced by normative pressures from without and within which leads the organisation to be guided by previously legitimated policies which over time have become standard operating practice. The legitimated policies have had the tendency to lead to isomorphism within the Arts Council environment, creating selected patterns of routine and continuity. A form of 'constructive tension' has arisen between that which is deemed necessary to preserve and that which must change with time.
\end{abstract}

Keywords: Arts policy; Resource, Political, Cultural processes

Corresponding author: e-mail: jrtattersall@ live.co.uk

Received 31 Aug. 2017 - Accepted 11 Dec. 2017

This is an Open Access article distributed under the terms of the Creative Commons Attribution-Non-Commercial-No Derivatives License (http://creativecommons.org/licenses/by-nc-nd/4.0/), which permits non-comercial re-use and distribution, provided the original work is properly cited, and is not altered or transformed in any way. 


\section{Introduction}

This paper applies some concepts and theories in the fields of strategic management and organisational behaviour to a study of the Council, as reflected through its policies, in the belief that relatively few attempts thus far have been made by academics to relate some of the profound difficulties of the public administration of art to these branches of the sciences. The author has sought not to bind himself to one particular model or strand of theory, in the belief that drawing on concepts and ideas in an appropriately focused yet eclectic fashion helps provide some answers at least, often missing from other discourses on the subject around the central question of why the Arts Council has never in its long history managed to formulate a comprehensive policy for the arts or settle once and for all its role as government appointed patron for the arts.

\section{Background}

Of growing academic interest to students of organisational theory and social policy is the increasing intervention of governments in 'late capitalist societies' which displays a desire to provide a measure of protection to those areas of the economy known to be at 'high risk' and which require constantly substantial amounts of financial, technical and manpower resources. ${ }^{1}$ This is so to the extent that governments have for some time now been intervening in the productive processes of a number of arts constituencies around the world, yet these protective and interventionist state strategies have oftentimes had the side effect of generating unintended consequences of 'fiscal crises' and 'ideological crises' that in some cases have produced severe internal contradictions for organisations like the Arts Council, which cannot always be

\footnotetext{
${ }^{1}$ For a recent and widely recognised example of this, one need look no further than the intervention of world governments in the "global financial crisis" of late 2008.
} 
contained within existing structures, programmes and processes and have had serious implications for the development of strategy as a whole.

Government's growing concern about value for money in public policy delivery and its determination to move policy-making and implementation nearer to the 'market' for that service has shaken the premise upon which the Arts Council was founded. The legislative mandate given to the Arts Council at its inception and carried forward to its later reincarnations was to foster, develop and promote the arts (always specified in the broadest of terms) and to increase its availability and accessibility to the public. With the advent of new technologies and new art forms, the Council has been faced with the decision to conserve the traditional or to develop the innovative, adopting where appropriate a more entrepreneurial approach in conjunction with partner organisations and individuals. Additionally, conflict has arisen in protecting its 'arm's length' status from government who see it as their prerogative to shape the arts to the current social policy preoccupations. The arm's length principle is politically ambiguous, perhaps deliberately so. The Council, therefore, is something of an anomaly being at the same time both part of and separate from government. In summary, the Arts Council lives in a constant state of tension; on the one hand between conflicting ideas partly engendered by the phenomenal growth of the arts in the post-war period and, on the other hand, between the expectations of the artistic community and the perceptions of its performance by government. Throughout its chequered history, the Arts Council has struggled with the question of excellence versus accessibility. Should it give priority to improving the artistic quality of the arts or to extending the availability of the arts to audiences in more parts of the country with the possible risk of limiting of, or dilution of, quality? In the 1960s and early 1970s there were occasions when it appeared it might be able to do both but as inflation grew astronomically and 
budgets became erratic, the Arts Council found itself having to make choices among programmes and clients, a situation it has had to revisit on many subsequent occasions. In addition, some clients (in the main, national companies) had on the basis of more or less guaranteed levels of funding, got used to attaining lavish levels of production which increased greatly the demands on the limited funds of the Council and heralded the era of the so-called 'Funding Trap'. With the emphasis in approach to funding (if not always in monetary terms) now demonstrably changing in favour of access the Arts Council, in trying to find an equitable solution, set limitations on the number of a particular type of client supported and on the sub disciplines eligible for funding.

A natural follow-on from questions of access and excellence are the related concerns of professional arts versus amateur arts, traditional art forms versus new art forms and individuals versus organisations. Emphasis in funding has typically over the years been given to professional artists who by and large come from the 'high arts' organisations for it is in funding these choices that the Arts Council feels most safe. However, the Council must still decide what emphasis and ultimately what proportion of its funds should be allotted to such areas as community style arts (these days also represented by professionals) or other speculatively formed entrepreneurial-type activities — in the sense of being innovative and risk takingwhich may not always be of a significant quality but are offering people the opportunity to participate and gain first-hand experience of the arts. Somewhat more recent art forms on occasions falling within traditional art forms i.e. media art and performance art only served to heighten the dilemma of the Council. It is these sorts of issues which are contextualised within the arguments around 'cultural democracy' and 'democracy of culture'. Nevertheless, despite earlier reservations, the Arts Council has come to recognise the need to provide a full range of 
support to the individual artist and has developed programmes to respond to these needs. However, when one examines the expenditures for the Council, it is evident that the larger proportion of money has always gone to the established arts organisations and recent policy statements have done little to dispel consensus over long-standing funding patterns.

\section{Resource Processes}

There are two issues which should permit comparative evaluation of the operating objectives and the resulting pattern of funding of the Arts Council. The first is the balance between support to the high, commercial and amateur arts. The second is the range of artistic disciplines and sub-disciplines supported, as well as responsiveness to new and emerging art forms. Historically, the Arts Council has tended to support traditional art forms in dance, music, opera, theatre, visual arts and literary writing. Emerging sub-disciplines are an on-going test of the Council's artistic judgement in recognising and adapting to new art forms in a timely manner thereby keeping pace with artistic, social and economic change.

Since its inception, the Arts Council has adopted 'excellence' as the strategic principle to guide funding. Excellence, however, is a relative term which involves the exercise of artistic judgement at various levels of artistic activity. There are two issues which should permit comparative evaluation of the policy objectives, and the resulting pattern of funding of the Arts Council. The first is whether the Council defines standards of excellence at the national, regional or local level. The second issue is the financial balance between support to artistic enterprises in the metropolitan areas as opposed to the regions. In effect, the tactic of the Arts Council has been to organise support into programmes-in-aid to individual artists and, more particularly, to arts organisations. Accordingly, a primary issue in evaluation of Arts Council funding is the balance between support to individual artists and arts organisations. In the case 
of arts organisations, the issue is the balance between support to larger 'flagship' institutions and smaller, emerging companies.

In preparation for what was in effect the third re-incarnation of its fifty-some year history the Arts Council (now called Arts Council England ${ }^{2}$ ) used its website to explain the ambitions of the 'new' organisation. The following are extracts:

Arts Council England is the national development agency for the arts. Between 2003 and 2006 we will invest $£ 2$ billion of public funds in the arts in England including funding from the National Lottery.

We want people throughout England to experience arts activities of the highest quality. We believe that access to the arts goes hand in hand with excellence.

The website went on to explain the resource ambitions of the re-named Council which are encapsulated under the following headings:

\section{The Arts Council and 'the arts'}

We will adopt a more modern definition of the arts, one that is open to current trends in emerging arts practice, in arts and technology, and in breaking down the boundaries between art forms, and between the arts and other disciplines.

\section{Placing artists at the centre}

The artist is the 'life source' of our work. In the past, we have mainly funded institutions (emphasis, the author). Now we want to give higher priority to the artist. We can do this indirectly through training, legislative change, or in stimulating the economy for artists. Or, we might provide direct assistance through more funding.

\footnotetext{
${ }^{2}$ Arts Council England went live in 2003. The original Arts Council of Great Britain was set up in 1946 with a change of name to Arts Council of England in 1994.
} 


\section{Our relationship with arts organisations}

Most of our funding will continue to go to our portfolio of 'regularly funded organisations' (emphasis, the author).

\section{Cultural diversity}

We will at the very least make more funding available specifically for culturally, diverse arts. We will also take steps to change the employment profile, governance and activities of both the Arts Council and the funded arts sector (emphasis, the author).

\section{Growth in resources for the arts}

We will draw up a plan for growth nationally and regionally, with some clear and challenging resource targets.

A concern to fund the best way to run an organisation prompts the question, 'best for what and for whom'? It assumes some goals which should be maximised using resources in the most effective and efficient way; but whose goals? Should they be the Arts Council's or those of the various sub cultures in existence? The question is how far the Arts Council is prepared to go in encouraging tendencies which may require significant modification of existing attitudes and administrative structures to accommodate new demands, or the revision of priorities for the allocation of resources, with all the attendant political implications that such changes will undoubtedly have and within the confines of a finite budget. Clearly the position in which the Arts Council has been placed is not an easy one. On the one hand, it sees the necessity to do something about the pressures and demands for a change to more community oriented art forms more entrepreneurial in nature and less institutionally based; on the other, it is conceivably reluctant to set in motion changes which could threaten its own established position which historically has demonstrated a preference for the established or 'high' arts and the institutions 
which underpin them, with the greater sense of accountability that it affords. Reasons behind the Arts Council's predilection for particular avenues of funding can perhaps be found in the Bower-Burgelman (Bower 1972; Burgelman 1983) explanation of strategy developing as the outcome of resource allocation routines in organisations as did others later (Noda and Bower 1996).

\section{Political Processes}

Agencies in their decision-making are affected by political considerations and by the wish to protect their own power and status. The political view of strategy development is, then, that strategies develop as the outcome of processes of bargaining and negotiation among powerful internal or external interest groups or stakeholders as they are often referred to today.

It is possible to construct two broadly competing images of what the Arts Council does. First, we might see the Council as formulating definite policy objectives in the arts, through some appropriate means of consultation and decision, and then proceeding to give effect to these by providing funds to various groups and individuals who are prepared and competent to carry out the required functions. A second view sees the Arts Council basically as an institution dispensing subsidies mostly to a range of well-established clients in the performing arts. These clients, in turn, view the Council as having a long-term, if not permanent, responsibility to support them and beyond that, help them expand. In total, their demands constitute a major charge against the Council which consequently finds itself left with very little financial or political room for manoeuvre or for the development of new policy initiatives despite, in part, a desire to do so.

Returning for the moment to the Bower-Burgelman view of strategy development, the procedures for deciding between competing proposals will include existing financial 
commitments and in-grained idealistic values of the kind already described. The reality is that despite the Art Council's references to a 'new' emphasis, the resolution of strategy is for the most part conditioned by financial imperatives and political manoeuvring in other quarters, and at other levels of the arts constituency than what would be conventionally thought of as strategic. The concept of 'non-decision' as advanced by Bachrach and Baratz (1970) appears as a useful analytical and explanatory tool in this context. From this ideological stance, demands or pressures for change in the existing allocation of resources or benefits in a particular sphere of activity can be suffocated or side-stepped before they are allowed to assume a dominant position. Thus, in studying the strategy of the Arts Council it would appear important to examine what the Council does not do, as much as what it does do. However, in reality an investigation of this type would not be straight forward, since the Council has on occasion acknowledged that often their reasons for doing or not doing something are found or lost (depending on one's viewpoint) in the 'interstices of administrative decisions', further complicated by the tendency to bury policy in their implicit assumptions about what is good for the arts community and people in general (Shaw 1980). Certain applications to the Council for grant aid are therefore regarded as 'legitimate' having been funded before or as 'appropriate', for as Schattschneider (1960) contends, 'political' organisations tend to develop a bias where some issues are organised into policy while others are organised out. In such situations, assistance to the arts and its 'justification' can be perpetuated without the need for objective assessment leading in time to legitimation of policies formulated and actions taken. Former Arts Council Chairman, Lord Goodman (1984), in an article in the Observer had occasion to remark when learning of the Council's most recent protestations that it was about to free itself 
from its traditional political constraints, that the idea suggested there was latitude available to it when in truth, there was not.

The practical implication of comments like this, as Johnson, Scholes and Whittington (2005) state, is that legitimacy is about meeting the expectations within an organisational field in terms of assumptions, behaviours and strategies. Drawing on the work of evolutionary theorists such as Aldrich (1999) and Weeks and Galunic (2003), they discuss the notions of selection through the lenses of function, fit, form and retention thought to depend on the extent to which policy and strategy is legitimised. Policies may have the 'function' of serving the interest or expectations of key individuals within the organisation. By 'fit' they mean policies and strategies are more likely to be successful in competing with other alternatives as they align with the culture and prior experience of the organisation more about which will be said in the next section on cultural processes. Of course, the reverse could also be the case, where it would be difficult to get new initiatives accepted because they are not seen as desirable or legitimate in terms of the way the organisation has traditionally operated. This brings us to the notion of 'form' by which is meant that some policies of strategy are by their very nature, more or less attractive, often from the outset, for the reasons thus stated. Accordingly, ideas of 'retention' are also sometimes used to support notions of legitimation. Strategies based on previous policies or ways of doing things are seen as the 'right way' to do things or best practice. Retention can also stem from the extent to which policies are attributed to powerful or influential people in or around the organisation, past or present. One need only reflect on the enormous influence John Maynard Keynes and successive Chairmen/Secretary Generals have had on the development of the Council and its policies, important aspects of which still influence the Council today. Thus, policies or strategies and their selection and retention will 
depend on the extent to which they are attractive to, and fostered by, a community of interest. Both selection and retention need to be seen as a part of an iterative process based on experience and cultural and political processes. In acceding to conformity and legitimation the Arts Council has wittingly or unwittingly institutionalised its policies and strategies over the years. Much of what has been said so far suggests the strong influence of forces for conformity. As researchers in institutional theory point out, innovation is not common; similarity is (Zucker, 1987). From what Minihan (1971) referred to as the nationalisation of culture in her book of that title has emerged (what some philosophers of art now term), 'the institutional theory of art'. This theory perceives art in terms of its social, institutional definition. The sociological nature of the institutional theory of art is self-evident, for the theory relies on the social roles and institutions, with all their incumbent financial, political, constitutional, managerial and moral considerations, and it is from this melting pot that art is now largely promoted and accredited. Thus, the Council, like it or not, is to a greater or lesser degree an organ of social policy and the institutional policies that come out of it are often a product of established practice. The 'political' and the 'aesthetic' are the inseparable, simultaneously present faces of the currency of the post-modern problematic. The putative freedom of the artist is constrained by the institutional legitimation process which imposes a grid of the permissible upon the field of the possible. Determinants and constraints will be submitted to the articulation of the "master discourse' of the institution which in turn is influenced by notions of professional standards and artistic values derivative of the organisational field in which the Arts Council finds itself. This is then reproduced through a network of self-constructed subjective meanings which become institutionalised over time. It cannot be described or explained without a detailed knowledge of the subjective logic which informs the construction of these institutional configurations and the 
dynamics of their historical transformation. One can see how in this way decisions, values and standards begin to be operationalised through an institution like the Arts Council.

Confronted with the task of having to make value-laden judgements, the Council has over the years developed guidelines to focus attention on particular facts and relationships and thereby both simplify and regularise the strategy process. Executives, administrators, policy makers, frequently make use of precedents, often urged to do so by those who would be affected by their actions particularly if this helps maintain a desired status quo. Drawing on the work of individuals such as, Lindblom (1959), Braybrooke and Lindblom (1963), Quinn (1980), Mintzberg and Waters (1985) and Johnson (1988), the strategy making processes at the Council could be characterised as both incremental and emergent in nature. In largely accepting or conforming to what has gone before, it is to be expected that changes in strategy will be incremental rather than revolutionary. Council strategy represents a continued dichotomy between 'past' and 'present', between 'product' and 'process' and as such has evolved through a series of compromises, rather than by means of a planned progression. One must not forget that one of the over-arching functions of the quango state in which the Council was placed was to enable it to commit itself to serving broad national ideals (the best for the most) without necessarily assuming all the political choices (what is the best for the most?). Political activity often results in emergent or incremental activity where subjective judgements and multiple demands on finite resources are to the fore as in the arts. On many occasions, finance unavoidably takes precedence and predisposes strategies to limitations, entrepreneurial or otherwise. Long-term planning, which may necessitate an up-front commitment to reform, together with associated costs, could assist in the development of a more comprehensive policy. This planning, however, is not largely attainable in the arts because of its predisposition to the 
mechanics of the public spending process which can be subject to drastic short-term fluctuations, especially when government finances are under strain. Where different views prevail and different parties seek to exercise their political will, compromise is more inevitable. In part, it would appear the Council has sought to protect what it sees as reasonably satisfactory working arrangements which have come about either through adoption or due process. This, in a quintessential way is what it has historically done believing its own brand of incrementalism to have achieved a modicum of success in moving with the times whilst safeguarding those canons which it holds most dear and upon which it bases all its fundamental strategies. On the other hand, the conflict and tensions that manifest themselves in the Council's political arena, arising as they do from different expectations or interests have on occasions prompted something of a paradigm shift as when community arts became a 'legitimate' activity for Council funding despite some twenty years of avoidance and neglect even though there was nothing in its founding charter which prevented it from doing so. Clearly there will be times when it is necessary to develop new concepts to guide future undertakings as well as to revise those arrangements which appear on close inspection not to have worked satisfactorily, or fairly, served the public interest. It is perhaps not surprising therefore that the Council has never pretended to pass ultimate judgement on its contribution, or settle once and for all the proper scope of its activities for after all, the Council's incremental policies are arguably only the mirror image of its own developing view of itself and its role in the arts.

\section{Cultural Processes}

The observed pattern of incremental strategy development of the Arts Council can be explained in terms of the outcome of the influence of organisational culture. Faced with forces for change the Arts Council has over the years conceivably sought to minimise the extent to which they 
have been faced with ambiguity and uncertainty over funding for the arts, by largely defining their strategies and policies in terms of that which is familiar. Changes around the periphery of policy as a reaction to developments in the artistic environment are approached incrementally. At any point in time, the selection of policies, strategies and events draws upon deeply held assumptions ever present in the organisation informing its behaviour whilst retention processes over time, describe the evolution of the organisation as a culture. As in the previous section, on political processes, the lenses of function, fit, form and retention are now once again considered in connection with selection but on this occasion more specifically in the context of cultural orientation.

Of these, 'function' might appear the most obvious. Policies or specific strategies may in part be selected because it is felt their phenotypic expression serves some particular function or takes the organisation towards a desired end. In the Arts Council's case attainment of these goals continues to be a challenge as it seeks to address its changing environment, meet the expectations of its numerous stakeholders whilst all the time operating in a realm of extreme subjectivity. Critics of the Council might well argue that they have often been wrong about the functionality of the strategies selected and adopted. Of course the Council has on numerous occasions and to varying degrees been shielded from the consequences of their decisions not least because of the fact that it receives the largest addition to its funds from the Government's annual grant-in-aid contribution (an underwriting luxury not available to most organisations) a situation conceivably enhanced by the arm's length principle which gives the Council a fair degree of latitude and not forgetting the professional efficacy which surrounds the decision making processes of the Council all of which perhaps forces them to conclude they are doing as well as can be expected. The Council has endeavoured to fulfil its interlocking 
responsibilities of developing and supporting the arts to a level of excellence whilst attempting to disseminate the arts as widely as possible. Strategies are as likely to be selected and promulgated because they are perceived as furthering local or individual aims as they are for furthering the aims of the organisation as a whole.

It is 'fit' more than function that sometimes structures and determines the selection process: strategies that fit with other dominant strategies are more likely to be selected, a fact which takes its cue from institutional theory. A theory of the cultural evolution of the organisation suggests there is a persuasive argument for bringing institutional theory to the table in an examination of organisational strategy and policy to look, first, at how the isomorphism that it predicts between the organisation and its environment actually evolves over time, and second, at how similar issues of legitimacy and social reproduction create selection patterns of continuity and routine. A central platform of the institutional theory is that choice and preferences cannot be properly understood outside the cultural and historical frameworks in which they are set (Powell and DiMaggio 1991). Organisations are often a product of their cultural orientation in much the same way that Mintzberg (1994) describes organisation strategies as retrospective rationalisations of behaviour. The present selection of strategies depends to a lesser or greater extent on the pattern of strategies selected in the past. At the Arts Council organisational level, policies and strategies are essentially made for it because its choices are frequently constrained by existing demands and pre-dispositions leading to replication.

Aside from function and fit strategies may be selected for their 'form'. In this context, they might be viewed as 'self-promoting' perhaps derivative of some management fad or particular ideological didactic. It is at this level of cultural process that ideas and values exist essentially 
in their own right, and it is at this level of analysis that such Parsonian concepts as, "total ideology' and 'collective representations' belong. Parsons, through his primary interest in the social system, witnessed how values can be internalised in an organisation as a 'set of beliefs, of expressive symbols, or of instrumental patterns which may be institutionalised in the sense that conforming to the standards in question may become a role-expectation for members of the collective; organised around conformity with morally sanctioned patterns of value-orientation shared by members of the collective in which the role functions' (Parsons and Shils 1962). The flagship philosophy referred to earlier to describe the process whereby a few companies in selected art forms are heavily subsidised to pursue excellence discriminates heavily in favour of art forms which not only cater to particular minority tastes, but which tend by their very nature to be among the most expensive manifestations of our culture and whilst most people today agree that it is still possible to talk meaningfully about something called 'excellence' they are far less sure about how it can be identified. Also, where a number of different activities have been identified as 'excellent' there is still the difficult task of deciding which is to be funded, as shortage of funds makes competition inevitable. Nor can the problem of selection be solved by counting heads, not least because the fact of providing subsidy can alter the number of heads to be counted. In addition to which, if excellence is the real determining factor when assessing applications, head counting becomes irrelevant. The right of these particular 'high arts' - or, more specifically, the right of the leading companies presenting them - to have a considerable proportion of their financial needs met by the community at large cannot be supported by logical evidence or rational argument. For some patrons of the arts it could be a matter of faith or personal belief whilst for the Arts Council it is arguably a matter of convention, a predisposition as suggested earlier which leads to a kind of self-perpetuation which in the final analysis is 
easier to entreat than contest- a form of lethargy, perhaps? In times of cut-backs the Arts Council has hitherto been criticised for its lack of specifics as to the reasons for the cut-backs. What has tended to be forthcoming from the Council could be described as propaganda used here not in a pejorative sense but rather to denote efforts to gain acceptance of policies by identifying them with what are considered to be generally held values and beliefs.

'Retention' occurs when selected policies are perpetuated, preserved, duplicated or otherwise reproduced. The idea of retention of certain preferred policies can be rooted in the identification of conflict within an organisation, the survival of such conflict only serving to reinforce those elements of retention. In the Arts Council's case, the absence of a clearly defined strategy for the arts when combined with the aforementioned funding trap has meant it has struggled over the years to the point of conflict to reconcile traditional cultural criteria and alternative contemporary conceptions of artistic and cultural development and worth. The need for regular (and often high degrees of) subsidy tends to be considered synonymous with the value of the activity- not only do we know it to be art, but we believe it to be demonstrably some of the best examples of art otherwise why would the Council spend the greater proportion of the available money on it? In such situations, assistance to particular art forms and their producing companies together with the accompanying justification can be perpetuated without any real degree of objective assessment. It is these processes at work in organisations that leads to the replication, perpetuation and preservation of policies as they develop such that they become routine and thus retained, eventually to become embedded in the culture of the organisation. As previously inferred, ownership of particular policies or ideological stances by powerful or influential individuals/stakeholders can heavily influence the replication of activities in the organisation thus leading to retention and legitimation. 


\section{Conclusions}

The Arts Council is influenced by normative pressures sometimes arising from external sources, other times arising from within the organisation itself. Under some conditions, these pressures lead the organisation to be guided by previously legitimated policies, which over time become standard operating practice.

Recent attention has been given to the perceived 'instrumentalism' of arts policy born out of a lack of clarity and consensus about what Arts Council England should be promoting. Not for the first time in the Council's history, the view has been expressed that in order to receive public money, artists and art organisations should be able to demonstrate that they have the potential to contribute to broad social and economic agendas arguably at the expense of their 'intrinsic' value and worth (Holden 2005). In 2006 Arts Council England set out to address this longstanding conundrum through a major public enquiry involving research and consultation to explore how members of the public value the arts and their priorities for public funding. In this context, it was suggested that instrumentalism had afforded the arts sector a measure of protection in the absence of clearly defined arts policy goals (Bunting 2008). Furthermore, as previously stated the adoption of legitimated policies has had the tendency to lead to isomorphism within the institutional environment, creating selected patterns of routine and continuity and ultimately increasing the probability of survival of both the Council and its policies.

If Arts Council England is to be effectively adaptive to accommodate both pre-existing and current demands it would seem that there must be a 'constructive tension' between that which is necessary to preserve and that which must be changed (Kanter 1983). A tension, for example, between the need for critics of the Council to question and challenge the preservation of core 
values and organisational 'mission'; between the need for new ideas and directions whilst maintaining a degree of continuity and preservation of those ideals deemed important in the arena of arts subvention and which also serve to justify the Council's continued existence.

This paper has considered the organisational dynamics of the Arts Council and the influences and pressures which characterise the institutional setting in which its policies are conditioned. By investigating this in the way it has been done, provides some clues as to what has been happening and some answers as to why things largely remain as they do. At its inception, the Arts Council was placed in a position and role where it could not ultimately hope to meet all the competing expectations arising from various individuals' ideological preconceptions and sympathies surrounding the arts and could at best only hope, in the language of H.A. Simon, to 'satisfice' (Simon 1962). Where there is a need for a compromise solution, a satisficing organisation will tend to be content to allow matters to continue in the way they always have done, at least up to the point where survival becomes threatened. Whether the Arts Council, as the present vehicle for much of the public funding of the arts, is best placed to patronise the arts for the next generation or whether other models of subvention previously identified (Cummings and Katz 1987; Tattersall 1988) offer a better solution remains open to ongoing question and debate.

\section{References}

Aldrich, Howard E. 1999. Organisations Evolving. London: Sage.

Bachrach, Peter, and Morton S. Baratz. 1970. Power and Poverty. New York: Oxford University Press. Bower, Joseph L. 1972. Managing the Resource Allocation Process: a study of Corporate Planning and Investment. Boston: Harvard Business School Press.

Braybrooke, David, and Charles E. Lindblom. 1963. A Strategy of Decision. London: Collier Macmillan. 
Bunting, Catherine. 2008. "What instrumentalism? A public perception of value." Cultural Trends 17 (4): 323-328.

Burgelman, Robert A. 1983. "A model of the interaction of strategic behaviour, corporate context and the concept of strategy." Academy of Management Review 81 (1): 61-70.

Cummings, Milton C. and Richard S. Katz, eds. 1987. The Patron State: Government and the Arts in Europe, North America and Japan, Oxford: Oxford University Press.

Goodman, Arnold. 1984. “The Case Against Arts Cuts." Observer, March 25

Holden, John. 2005. Capturing Cultural Value. London: Demos.

Johnson, Gerry. 1988. "Re-thinking incrementalism.” Strategic Management Journal 9:75-91.

Johnson, Gerry, Kevan Scholes, and Richard Whittington. 2005. Exploring Corporate Strategy. Harlow: Pearson Education Limited.

Kanter, Rosabeth M. 1983. The Change Masters: Innovation for Productivity in the American Corporation. New York: Basic Books.

Lindblom, Charles E. 1959. "The science of muddling through.” Public Administration Review 19:7988.

Minihan, Janet. 1971. The Nationalisation of Culture. London: Hamish Hamilton.

Mintzberg, Henry. 1994. The Rise and Fall of Strategic Planning. Hemel Hempstead: Prentice Hall.

Mintzberg, Henry, and James A. Waters. 1985. "Of strategies, deliberate and emergent." Strategic Management Journal 6 (3): 257-272.

Noda, Tomo, and Joseph L. Bower. 1996. "Strategy as iterated processes of resource allocation." Strategic Management Journal 17:159-192.

Parsons, Talcott, and Edward A. Shils. 1962. Towards a General Theory of Action. New York: Harper and Row.

Powell, Walter W., and Paul J. DiMaggio. 1991. The New Institutionalism in Organisational Analysis. Chicago: University of Chicago Press.

Quinn, James B. 1980. Strategies for Change:Logical Incrementalism. New York: McGraw-Hill.

Schattschneider, Elmer E. 1960. The Semi-Sovereign People. New York: Holt, Rhinehart and Wilson.

Shaw, Roy. 1980. "Problems of Evaluation." London: Arts Council of Great Britain, 183.

Simon, Herbert A. 1962. "New Developments in the Theory of the Firm." The American Economic Review 52 (2): 1-15.

Tattersall, John R. 1988. "A Strategy for the Arts: Five Nation Study of Arts Supports Systems.” PhD diss., City University. <http://openaccess.city.ac.uk/7401/> .

Weeks, John R., and Charles Galunic. 2003. "A theory of the cultural evolution of the firm: the intraorganisational ecology of memes.” Organisational Studies 24 (8): 1309-1352. 


\section{Journal of Evolutionary Studies in Business}

Volume 3, Number 1, 226-246, January-June 2018

doi:10.1344/jesb2018.1.j043

Zucker, Lynne G. 1987. "Institutional Theories of Organisation.” The Annual Review of Sociology $13: 443-464$

This is an Open Access article distributed under the terms of the Creative Commons Attribution-Non-Commercial-No Derivatives License (http://creativecommons.org/licenses/by-nc-nd/4.0/), which permits non-comercial re-use and distribution, provided the original work is properly cited, and is not altered or transformed in any way.

Online ISSN: 2385-7137

http://revistes.ub.edu/index.php/JESB
COPE Committee on Publication Ethics Creative Commons License 4.0 Cccreative 